\title{
DIMINUTIVITY AND EVALUATION IN COURTROOM INTERACTION: PATTERNS WITH LITTLE (PART 1)
}

Keywords: courtroom talk, diminutivity, diminutives, evaluation, stance

\begin{abstract}
This article presents the results of a corpus-assisted discourse study into the use of the diminutive marker little in an adversarial trial. It explores the recurrent patterns and the evaluative meanings associated with the use of little, and furthermore looks at the broader interactional context in which these patterns and meanings are found. Drawing on the concepts of stance (du Bois 2007), evaluation (Hunston 1994) and semantic prosody (Louw 1993), it demonstrates how interactants in the courtroom setting lay claim to epistemic priority by stressing the relevance of their own testimony while discrediting the opponent and diminishing the importance of unwanted evidence. The analysis also shows that patterns with little are linked to politeness and mitigation, and that they soften the austerity of communication. The data seem to suggest as well that the evaluative uses of little are more common in references to the primary reality of the courtroom than in references to the out-of-the-courtroom reality, in the case of which denotative meanings prevail. Most importantly, however, the study reveals that despite the formality of courtroom interaction, analytic diminutives with little are a frequent interactional device and, further, that their polarities depend on interplay with other discourse elements as well as the interpersonal goals that the speakers are trying to achieve.
\end{abstract}

Mary, what is this? I find that you have had a baby! Please, ma'am, it's only a little one. ${ }^{1}$

\footnotetext{
I quote this supposed exchange between a Victorian mistress of the house and a housemaid after the Opinion of Advocate General Sharpston dated 15 September 2011. The full text of the Opinion is available at: http://eur-lex.europa.eu/legal-content/EN/ALL/?uri=CELEX\%3A62010CCo465 (date of access: 5 May 2017).
} 


\section{Introduction}

While it has been acknowledged that "evaluation does not have structures of its own" and that it is, in fact, "parasitic on other structural elements" (Thompson 1997: 65), the role of syntactic diminutives with little in conveying attitudes and assessments in professional settings has not attracted much attention in stance-related scholarship. Similarly, despite the wealth of publications that delve into the fabric of courtroom interaction, most notably the strategies of questioning, patterns with little seem to have escaped the attention of discourse analysts working with trial data. That is not to say, of course, that the evaluative potential of syntactic diminutives has been entirely overlooked, since there are a number of studies focusing on the denotative and connotative meanings of diminutives in non-professional settings. They describe, for instance, the role of diminutivisation in conspiracy fiction (e.g. Gorzycka 2012) and children's literature (e.g. Biały 2012) as well as the usefulness of this linguistic resource in "modesty" and "hospitality" contexts (see, e.g., Biały 2013; Schneider 2013). However, the interactional practices which involve the use of little $+\mathrm{N}$ diminutives specifically in courtroom discourse have not been sufficiently explored, despite their pragmatic usefulness for varying the strength of the assertions through which legal evidence is ultimately constructed. It is therefore the aim of this study to demonstrate that various patterns with diminutives play a not-so-little role both in intersubjective positioning and in attributing much or little weight to the evidence presented in court.

\section{Diminutives and diminutive meaning}

Commonly considered as prototypical devices for expressing "smallness", diminutives have been approached from various perspectives and discussed cross-linguistically as part of the broader notion of diminutivity. This concept encompasses not only morphological diminutives, but also analytic (syntactic) diminutives as well as diminutive meaning (created thanks to such linguistic devices as, e.g., reduplication or compounding). ${ }^{2}$ As regards diminutive formation in English, the productivity of diminutive suffixes, of which $-y /$-ie, -let and -ette are most common, is low and English leans towards periphrastic constructions with the adjectives little and small. ${ }^{3}$ When it comes to defining the term "diminutive" itself, different positions can be found in the literature. For instance, Heltberg (1964: 95-96, quoted in Biały 2013: 5) distinguishes three types of diminutives: 1 ) "pure" diminutives which denote the smallness of the referent(s); 2) emotional and stylistic diminutives (including

2 For a discussion of various processes of diminutive formation across languages, see Schneider (2013: 137-140).

3 As Dressler and Barbaresi (1994: 114) observe, it is the "weak" little rather than the "normal" little which corresponds to the typical morphological diminutives in other European languages (e.g. Italian). 
hypocoristics) which convey the speaker's attitude towards the referent(s) and 3) diminutives which denote both the smallness of the referent(s) and the speaker's attitude.

Drawing on the concept of polysemy, Taylor (1995: 145-147, quoted in Biały 2013: 3-4), on the other hand, argues that diminutive meanings are derived from the core meaning of "small" through metaphor and metonymy. Thus, as he proposes, metaphorization entails the transfer of the notion of smallness from the spatial to the non-spatial domain (e.g. short temporal duration, reduced strength, reduced scale and reduced extent or intensity), while metonymy involves the extension of the diminutive to express attitude (e.g. affection/tenderness, a lack of worth/depreciation, non-importance, approximation and intensification). Likewise, Gorzycka (2012: 153) sees diminutives as "constructions denoting smallness with all of the accompanying literal and metaphorical meanings, including small social distance, as well as with the positive and negative attitudes associated with those meanings", which, it should be added, is the position adopted in the current study. Needless to say, the positive and negative attitudes signalled by diminutives typically involve some form of appreciation (e.g. affection, tenderness, sympathy, hospitality, politeness, playfulness, informality, intimacy or approval) or depreciation (e.g. disrespect, contempt, non-importance, irony, distance or mockery) (Biały 2013: 6).

At this point, the affectionate or endearing effect of diminutives in child-centred speech situations should also be mentioned, given that adult-child interactions and caretaker speech are seen as the prototypical contexts for the use of diminutives (Schneider 2003: 233-234). It should be clarified too that child-centred speech situations are those in which a child participates either as a speaker, addressee, "ratified listener" or an absent topical referent (Dressler, Barbaresi 1994: 173). In such situations - as Dressler and Barbaresi propose - the diminutivum puerile ${ }^{4}$ realises the pragmatic features [small] and [non-serious], in agreement with the assumption that children are non-serious participants of the speech situation and that only adults can take full responsibility for their commitments and ensure the seriousness of the speech act itself. ${ }^{5}$ Interestingly, "child-centred" speech situations can be recreated metaphorically in the language of love or in speech acts involving animals, or, in general, in reconstructions of a child's world (Dressler, Barbaresi 1994: 147). Child-centred diminutives can thus achieve the effects of affection, tenderness, or even solidarity.

That said, the pragmatic meanings of diminutives that relate to 'politeness', 'modesty' and 'hospitality' have, in turn, been highlighted in Jurafsky (1996) and Schneider (2013). Just as Jurafsky (1996: 558) stresses, the role of diminutives in expressing politeness, consisting inter alia in the reduction of imposition and the "softening" of requests and offers, so too does Schneider (2013: 148), drawing

The label was introduced by Staverman (1953).

5 Defending their approach to diminutives, Dressler and Barbaresi (2001: 50) also note that senile people, just like children, are treated as non-serious participants and that therefore they, too, are often addressed with diminutives. 
attention to the role of diminutiva modesta in playing down one's achievements or the value of one's possessions. ${ }^{6}$ Elsewhere, Schneider and Strubel-Burgdorf (2012: 29) observe that while diminutives referring to objects or animals tend to be used for quantification, those referring to persons tend to involve evaluation, which - as their findings indicate - is predominantly negative. In a similar vein, the priority of emotive meanings over the denotative meaning of smallness is stressed by Alonso (1933/1961: 167-169, quoted in Dressler, Barbaresi 1994: 87), who notes that they depend on the context, the participants' attitudes and the speech act itself. Such an "emotionalist" approach to diminutives (represented also by Volek 1987) has, however, been criticised by Dressler and Barbaresi, who assert that "[e]motive meaning can be attributed only where it is clearly discernible" (Dressler, Barbaresi 1994: 32).

\section{Evaluative and stance-related patterns in discourse}

As shown above, the affective and evaluative functions of diminutives in non-specialist English have been addressed in earlier studies. However, evaluative uses of various lexico-grammatical patterns with little and their semantic prosodies in a professional setting such as the courtroom have attracted considerably less attention, even though they can cast more light on where less explicit evaluation resides in institutional communication. It should also be explained at this point that the very term pattern refers to "the frequent behaviour of a given lexical item, expressed in a sequence of elements" (Hunston 2007: 30). ${ }^{7}$ The term semantic (evaluative) prosody, in turn, denotes a "consistent aura of meaning with which a form is imbued by its collocates" (Louw 1993: 157) or, to use a different wording, "the spreading of connotational colouring beyond single word boundaries" (Partington 1998: 68). ${ }^{8}$ From a CADS 9 point of view, the non-obvious meanings of routinised chunks of language emerge once large amounts of data are scrutinised. Along the same lines, CADS advocates believe that if "recurring instances of a phenomenon are noted, the explication of a single instance normally implies that a pattern has been identified, and the explanation would hold true for other similar instances" (Hunston 2007: 28). This approach has been successfully applied in analyses of explicit and implicit exponents of evaluation. To date, a number of evaluative and stance-related

\footnotetext{
Cf. Leech's (1983) Modesty Maxim.

7 It should also be noted here that the term pattern has a broader meaning than the terms $n$-gram, lexical bundle or cluster, with the latter three referring to continuous sequences of a specific number of words.

8 For a more thorough discussion of semantic prosody, see, e.g., Morley, Partington (2009).

9 The aim of Corpus-Assisted Discourse Studies (CADS) is "the uncovering, in the discourse type under study, of what we might call non-obvious meaning, that is, meaning which might not be readily available to naked-eye perusal". This meaning becomes accessible by combining the quantitative approach (i.e. overviews of large amounts of a given discourse type) with the qualitative one (i.e. a detailed analysis of individual stretches of discourse) (Partington 2008: 97).
} 
patterns have been identified in various settings, including media discourse (see, e.g., Clark 2009; Lombardo 2009; Venuti, Nasti 2014), political genres (see, e.g., Miller, Johnson 2009; de Candia et al. 2013) and legal argumentation (see, e.g., GoźdźRoszkowski, Pontrandolfo 2013; Pontrandolfo, Goźdź-Roszkowski 2015). What these studies clearly demonstrate is that evaluation can be implicit and that less tangible ways of expressing value judgements may escape notice, particularly if they are not considered from a corpus perspective.

That being said, note should also be taken of the concept of stance, which is inextricably intertwined with evaluation, although its relation to evaluation is defined in a variety of ways. For instance, in Hunston's approach, stance refers to indications in the text that the writer is communicating with the reader, while evaluation denotes attribution of a value to an entity, whether inside or outside a text (Hunston 2011: 51). Both concepts, in turn, are subsumed by the overarching notion of evaluative language, which involves the expression of "an attitude towards a person, situation or other entity" and which "is both subjective and located within a societal value system" (Hunston 1994: 210). Importantly, Hunston (2007: 39) stresses the fact that both stance and evaluation are cumulative - i.e. they are identifiable across whole phrases, paragraphs and discourses - and she admits that their embodiments can indeed be "difficult to pin down". The label stancetaking, on the other hand, is favoured by interactional linguists who analyse spoken data and work within the conversation-analytic paradigm, and who hold the view that intersubjective meanings are sequentially co-constructed in interaction. ${ }^{10}$ Seen from this perspective, stance is defined as a form of social action that entails the mutual positioning of subjects and the evaluation of objects (du Bois 2007). ${ }^{11}$ Despite their different analytical procedures, both the approaches referred to above recognise the fact that stance does not reside in single forms and so they believe that attitudinal meanings are, accordingly, dispersed in discourse or constructed sequentially in interaction. In the following analysis, I draw on both approaches.

10 Like interactional linguists, Hunston (2007: 46), too, admits that "stance meaning is also distributed across larger interactional units" and, further, that a broader qualitative analysis of stance involves not only the study of phraseologies, but also of "turns-at-talk, interactional sequences, and intertextuality".

11 Du Bois' (2007) understanding of stance is visualised as "the stance triangle", i.e. as the relation holding between the interlocutors and a discourse object. However, as Debras argues, this model does not account for the speakers' multimodal enactment (e.g. pitch variation, pantomime) of their distancing from a stance attributed to an absent subject. Therefore, as she proposes, the stance triangle should be redefined as the stance tetrad, "where speakers position themselves with respect not only to an object and a present subject but also to absent subjects" (Debras 2015: 95). Interestingly, although the current research is not conceived of as a multimodal study and, consequently, it does not examine the manner in which trial participants use multimodal enactment to express various viewpoints and assessments, it does show a difference between the deployment of patterns with little referring to the co-present discourse participants and the ongoing interaction (primary reality), on the one hand, and those referring to spatially and temporally remote subjects and objects (secondary reality). As will be shown in Section 4.3, in the latter case, the negative polarity of patterns with little is much less visible than in the case of references to the primary reality of the courtroom. 


\section{Little and evaluation in courtroom talk}

\subsection{Aims, data and method}

The present study seeks to demonstrate that little is a useful evaluative resource which recurs in courtroom interaction. More precisely, its goal is, firstly, to determine the extent to which patterns with little are deployed in courtroom talk and, secondly, to interpret their pragmatic meanings and evaluative leanings in the contexts analysed. To this end, I chose transcripts from an adversarial trial (totalling app. 1.5 million words $)^{12}$ as my data source. ${ }^{13}$ This material, it needs to be added, exemplifies the kind of highly confrontational interaction which takes place in a formal, institutional setting. As such, it is marked by a great social distance between the participants and a consequent unequal distribution of institutional and interactional power. Needless to say, antagonism and hostility are detectable especially in the competitive discourses of the claimant and the counsel, since their primary communicative goal is not so much to transmit new information, but to discredit the opponent and his testimony in front of the audience (i.e. the judge).$^{14}$ As will be shown, these situational parameters have a bearing on the interactional strategies used by the speakers and, thus, on their selection of patterns with little.

As previously noted, in the current analysis it is assumed that stance does not belong to individual forms, but rather, that it is "a meaning, a type of meaning, or several types of meaning" (Hunston 2007: 27) and, consequently, that its identification in discourse entails more than simply locating individual lexical items. It is also believed, in line with Hunston (2007: 28), that in order to interpret the role played by stance, the analyst needs to look at the discourse as a whole, and not just at the immediate co-text of the target form. Therefore, building on the interactional concept of stance, on the one hand, and the notion of evaluative patterns in discourse, on the other, the study aims to demonstrate that such patterns also underpin (or provide a type of "scaffolding for") the sequential co-construction of stance, contributing to the "consistency of evaluation at local points" or "evaluative harmony" (Partington et al. 2013: 55) of the discourse produced by individual trial participants. Evaluative patterns are thus shown to underlie the interactional practices which reveal the interactants' attitudes towards their interlocutors and convey their assessments of the utterances they hear or produce.

The analysis itself started with a corpus query using the Concord tool of WordSmith Tools (version 6) (Scott 2012), with little employed as the search word. Following a careful reading of the concordance lines, as well as an analysis of the most frequent left and right collocates of little, I chose a selection of patterns with little for

12 The transcripts were downloaded from: http://www.hdot.org/en/trial/transcripts/index.html (date of access: 31 January 2013).

13 Since the data come from one adversarial trial, the findings reported here may not be relevant to courtroom talk in general and, in particular, to less confrontational types of proceedings. Therefore, more research is needed for valid conclusions to be drawn about the usage of little in other subtypes of courtroom discourse.

14 The material used in the analysis comes from a bench trial, i.e. one in which no jury is present. 
a more detailed, contextual analysis. During a qualitative examination of selected clusters and co-occurrences, ${ }^{15}$ I considered their frequencies, syntactic behaviour, the type of environment in which they occur (positive vs. negative), and the roles of the participants in the interaction. The findings of this investigation including a general overview of patterns with little and a contextual analysis of selected patterns with little are reported in Part 1 and Part 2 of the article, respectively. ${ }^{16}$

\subsection{Selected patterns with little in courtroom talk}

\subsubsection{General overview of patterns with little}

A preliminary corpus query showed that little was the most frequent diminutive marker ( 769 tokens), followed by a bit (293 tokens) and the significantly less frequent: small (196 tokens), tiny (39 tokens), slight (26 tokens), thin (19 tokens), wee (4 tokens), petty (3 tokens) and teeny (1 token). Regarding 2- and 3-word clusters with little attested by the data (Table 1), in turn, the items a little and little bit turned out to be the most common ( 276 and 121 tokens, respectively). ${ }^{17}$ Quite unexpectedly, little bundle had a relatively high frequency, too (98 tokens). Other, less frequent, clusters included for instance: this little (52 tokens) and that little (47 tokens) as well as my little (19 tokens) and your little (15 tokens).

\begin{tabular}{|c|c|c|}
\hline Clusters & Raw score & Normed score ${ }^{17}$ \\
\hline a little & 276 & 193.4 \\
\hline little bit & 121 & 84.8 \\
\hline the little & 116 & 81.3 \\
\hline a little bit & 114 & 79.9 \\
\hline little bundle & 98 & 68.7 \\
\hline
\end{tabular}

15 The analysis included both 2- and 3-word clusters (e.g. my little and a little bit), with the cutoff point established at 15 tokens, and co-occurrences of little with selected discourse items (e.g. evaluative adjectives and "diminutive" nouns), the latter of which were identified and counted manually.

16 Although the focus of the current study is on syntactic diminutives with little rather than those of a morphological nature, the method used in the study complies in essence with the principles which Schneider and Strubel-Burgdorf (2012: 30) outline for investigations of "proper" diminutives. To be exact, Schneider and Strubel-Burgdorf believe that such analyses should be empirical, rather than intuitive; that qualitative analysis should be combined with quantitative analysis; that quantitative analysis should be based on large electronic corpora; that diminutives should be examined in the context of the discourse unit in which they occur; that sweeping generalisations should be avoided (given that diminutives are subject to variation, differences across medium, language variety, genre, style and situation) and, finally, that each diminutive suffix (e.g. -let) and each diminutive formation (e.g. wifelet) should be examined individually.

17 It should be noted that the frequencies shown in Table 1 are not mutually exclusive. For instance, the frequency of a little is included in the frequency of a little bit.

18 The normed score shows frequency per million words. 


\begin{tabular}{lcc}
\multicolumn{1}{c}{ Clusters } & Raw score & Normed score $^{17}$ \\
\hline the little bundle & 54 & 37.8 \\
this little & 52 & 36.4 \\
that little & 47 & 32.9 \\
very little & 36 & 25.2 \\
little clip & 34 & 23.8 \\
little bit of & 32 & 22.4 \\
of the little & 28 & 19.6 \\
little bundle of & 22 & 15.4 \\
these little & 21 & 14.7 \\
my little & 19 & 13.3 \\
little bundle I & 15 & 10.5 \\
your little & 15 & 10.5
\end{tabular}

Table 1. 2- and 3-word clusters with little

As for noteworthy co-occurrences, the use of little with reference to spoken and written communication accounted for about $40 \%$ of all occurrences (307 tokens). On the other hand, co-occurrences with evaluative adjectives, diminutive adjectives and diminutive nouns were much rarer (Table 2). Some of the above-mentioned patterns will be presented and discussed in detail in Part 2 of the article.

\begin{tabular}{lcc}
\multicolumn{1}{c}{ Co-occurrences with little } & Raw score & Normed score \\
\hline $\begin{array}{l}\text { little + references to spoken and written } \\
\text { communication }\end{array}$ & 307 & 215.1 \\
$\begin{array}{l}\text { evaluative adjective + little + noun } \\
\text { little + diminutive noun }\end{array}$ & 22 & 15.4 \\
little + evaluative adjective + noun & 7 & 4.9 \\
little + diminutive adjective + noun & 6 & 4.2 \\
diminutive adjective + little + noun & 6 & 4.2 \\
evaluative adjective + little + evaluative & 5 & 3.5 \\
adjective + evaluative adjective + noun & 1 & 0.7
\end{tabular}

Table 2. Selected co-occurrences with little 


\section{References}

Alonso A. 1933/1961. Noción, emoción, acción y fantasía en los diminutivos. - Alonso A. (ed.). Estudios linguisticos: temas españoles. Madrid: 161-189.

Biały P. 2012. Synthetic diminutives in English nursery rhymes: Formations with the suffix -ie. - Prace Naukowe Akademii im. Jana Długosza w Częstochowie 8: 113-121.

Biały P. 2013. On the priority of connotative over denotative meanings in Polish diminutives. - Studies in Polish Linguistics 8.1: 1-13.

Bois J.W. du. 2007. The stance triangle. - Englebretson R. (ed.). Stancetaking in discourse: Subjectivity, evaluation, interaction. Amsterdam, Philadelphia: 139-182.

Candia S. de, Spinzi C., Venuti M. 2013. "I don't know the answer to that question": A corpusassisted discourse analysis of White House press briefings. - Critical Approaches to Discourse Analysis across Disciplines 7.1: 66-81.

Clark C. 2009. "Either you are with us, or you are with the terrorists': How UK and US television news reported the 2003 Iraq conflict. - Morley J., Bayley P. (eds.). Corpus-assisted discourse studies on the Iraq conflict. Wording the war. London, New York: 165-185.

Debras C. 2015. Stance-taking functions of multimodal constructed dialogue during spoken interaction. - Ferré G., Tutton M. (eds.). Gesture and speech in interaction. [4th edition]. Nantes: 95-100.

Dressler W.U., Barbaresi L.M. 1994. Morphopragmatics: Diminutives and intensifiers in Italian, German and other languages. Berlin.

Dressler W.U., Barbaresi L.M. 2001. Morphopragmatics of diminutives and augmentatives: On the priority of pragmatics over semantics. - Kenesei I., Harnish R.M. (eds.). Perspectives on semantics, pragmatics, and discourse. Amsterdam, Philadelphia: 43-58.

Gorzycka D. 2012. A note on diminutive types and functions in English: A case study of diminutive use in Dan Brown's The Da Vinci Code. - Głaz A., Kowalewski H., Weremczuk A. (eds.). What's in a text? Inquiries into the textual cornucopia. Newcastle upon Tyne: 149-163.

Goźdź-Roszkowski S., Pontrandolfo G. 2013. Evaluative patterns in judicial discourse: A corpus-based phraseological perspective on American and Italian criminal judgments. International Journal of Law, Language and Discourse 3: 9-69.

Heltberg K. 1964. O deminutywach i augmentatywach. - Prace Filologiczne 18.2: 93-102.

Hunston S. 1994. Evaluation and organisation in academic discourse. - Coulthard M. (ed.). Advances in written text analysis. London: 191-218.

Hunston S. 2007. Using a corpus to investigate stance quantitatively and qualitatively. Englebretson R. (ed.). Stancetaking in discourse: Subjectivity, evaluation, interaction. Amsterdam, Philadelphia: 27-48.

Hunston S. 2011. Corpus approaches to evaluation. Phraseology and evaluative language. London, New York.

Jurafsky D. 1996. Universal tendencies in the semantics of diminutives. - Language 72.3: 533-578.

Leech G. 1983. Principles of pragmatics. London.

Lombardo L. 2009. Positioning and stance in TV news reporting of the 2003 Iraq war: The anchor on CBS and the news presenter on BBC. - Morley J., Bayley P. (eds.). Corpusassisted discourse studies on the Iraq conflict. Wording the war. London, New York: 141-164.

Louw B. 1993. Irony in the text or insincerity in the writer? The diagnostic potential of semantic prosodies. - Baker M., Francis G., Tognini-Bonelli E. (eds.). Text and technology: In honour of John Sinclair. Amsterdam, Philadelphia: 157-176. 
Miller D.R., Johnson J.H. 2009. Strict vs. nurturant parents? A corpus-assisted study of congressional positioning on the war in Iraq. - Morley J., Bayley P. (eds.). Corpus-assisted discourse studies on the Iraq conflict. Wording the war. London, New York: 34-73.

Morley J., Partington A. 2009. A few frequently asked questions about semantic - or evaluative - prosody. - International Journal of Corpus Linguistics 14.2: 139-158.

Partington A. 1998. Patterns and meanings: Using corpora for English language research and teaching. [= Studies in corpus linguistics 2]. Amsterdam, Philadelphia.

Partington A. 2008. The armchair and the machine: Corpus-assisted Discourse Research. Taylor Torsello C., Ackerley K., Castello E. (eds.). Corpora for university language teachers. Bern: 95-118.

Partington A., Duguid A., Taylor C. 2013. Patterns and meanings in discourse. Theory and practice in corpus-assisted discourse studies (CADS). Amsterdam, Philadelphia.

Pontrandolfo G., Goźdź-Roszkowski S. 2015. Exploring the local grammar of evaluation: The case of adjectival patterns in American and Italian judicial discourse. - Research in Language 12.1: 71-91.

Schneider K.P. 2003. Diminutives in English. Tübingen.

Schneider K.P. 2013. The truth about diminutives, and how we can find it: Some theoretical and methodological considerations. - SKASE Journal of Theoretical Linguistics 10.1: 137-151. [available at: http://www.skase.sk/Volumes/JTL22/pdf_doc/08.pdf].

Schneider K.P., Strubel-Burgdorf S. 2012. Diminutive -let in English. - SKASE Journal of Theoretical Linguistics 9.1: 15-32. [available at: http://www.skase.sk/Volumes/JTL20/ pdf_doc/02.pdf].

Scott M. 2012. WordSmith Tools (version 6). Stroud.

Staverman W.H. 1953. Diminutivitis neerlandica. De Gids 116: 407-419.

Taylor J.R. 1995. Linguistic categorization: Prototypes in linguistic theory. Oxford.

Thompson G. 1997. Introducing functional grammar. London.

Venuti M., Nasti C. 2014. The Lisbon Treaty and the British press. A corpus-based contrastive analysis of evaluation resources. - Research in Language 12.1: 27-47.

Volek B. 1987. Emotive signs in language and semantic functioning of derived nouns in Russian. Amsterdam, New York. 